\title{
La teoría de la percepción en la Filosofía del Entendimiento de Andrés Bello $^{1}$
}

\author{
Juan José Rosales Sánchez²
}

Recibido: 31 de mayo de 2017 / Aceptado: 15 de diciembre de 2018

Resumen. Este artículo estudia, desde un punto de vista analítico, la teoría de la percepción que Andrés Bello presenta en su Filosofía del Entendimiento. El objetivo central consiste en elucidar cuáles son los elementos que componen y estructuran el proceso de la percepción. En este sentido, se procede mediante el análisis de los capítulos y los apéndices relacionados con los temas de la percepción, que corresponden con la primera parte denominada, "Psicolojía mental". De conformidad con lo anterior, se analizan las nociones de alma o espíritu, conciencia, sensación, intuición, referencia o juicio, e impresión. Metodológicamente, se recurre a las estrategias y recursos que para el trabajo filosófico provee el análisis del lenguaje. Finalmente, se concluye que la teoría de la percepción en Andrés Bello, involucra la colaboración de una serie de subprocesos como la intuición, la sensación y la referencia o juicio, además de reclamar como indispensable la unidad e indivisibilidad del alma o el "yo".

Palabras clave: Alma o conciencia; intuición; percepción; referencia; sensación.

\section{[en] The theory of perception in the Filosofía del Entendimiento of Andrés Bello}

\begin{abstract}
From an analytical framework this paper studies the perception theory posed by Andres Bello in his Filosofia del Entendimiento. The principal aim consists on elucidate the elements which make up and built up the perception process. In this sense, the procedure is supported by the chapters and appendix analysis related to the perception issue which are in the first part so-called "Psicolojía mental". According to these, the concepts of soul, spirit, conscious, sensation, intuition, reference or judgement, and impression are analyzed. Methodologically, strategies and resources provided by language analysis from the philosophical frame are the tools used for this work. Finally, the conclusion points out that the Andres Bello perception theory involves a sort of collaborating job from several sub-process such as intuition, sensation, and reference or judgement, and that is claiming as fundamental the soul or "self" unity and indivisibility as well.
\end{abstract}

Key words: Intuition; perception; reference; sensation; soul or consciousness.

Sumario: 1. La filosofía y sus tareas; 2. Qué es la percepción; 3. Qué es la sensación; 4. Percepción y sensación; 5. Variedades de la percepción; 6. Unidad primigenia y multiplicidad; 7. Referencias bibliográficas.

1 Este artículo recoge algunos resultados de la investigación "Contenidos, conocimiento y experiencia. Proyecto en epistemología”, financiado por la Universidad Yachay Tech, Ecuador, de diciembre 2014 a diciembre 2015.

2 Universidad Yachay Tech, Ecuador juanitove@gmail.com ORCID: 0000-0001-6203-317 
Cómo citar: Rosales Sánchez, J.J. (2019): “La teoría de la percepción en la Filosofía del Entendimiento de Andrés Bello", en Revista Anales del Seminario de Historia de la Filosofia 36 (1), 127-145.

\section{La filosofía y sus tareas}

Andrés Bello comienza su Filosofía del Entendimiento con la siguiente afirmación: "El objeto de la filosofía es el conocimiento del espíritu humano i la acertada dirección de sus actos" ${ }^{\prime \prime}$. No obstante, en el siguiente párrafo advierte, como si se tratara de responder a las preguntas ¿cómo se llega a conocer del espíritu humano?, y, ¿qué se conoce de él?, que "Nuestro espíritu no nos es conocido sino por las afecciones que experimenta i por los actos que ejecuta. De su íntima naturaleza nada sabemos"4. Pues bien, estos últimos juicios determinan la dirección de las investigaciones de la Filosofía del Entendimiento, que no es otra que la de averiguar en qué consisten las afecciones y actos del espíritu humano. Una vez que aclara qué está al alcance del conocimiento de la filosofía y qué no, entonces indica, de acuerdo con dos grandes esquemas, cuáles son las funciones de las afecciones y de los actos del espíritu. De las afecciones afirma que por medio de éstas el espíritu conoce, investiga la verdad y se asegura de que la posée"; de seguidas dice de los actos que con ellos el espíritu "quiere, apetece la felicidad y se esfuerza por alcanzarla y retenerla"s.

La distinción entre afecciones y actos forma la base para que Bello divida las ocupaciones de la filosofía en dos grandes campos de estudio, a saber: en un dominio propio para el análisis y comprensión de los fenómenos relativos a la mente (que también denomina entendimiento e inteligencia) y, otro destinado a escudriñar en los fundamentos de la conducta humana. Entonces, en la medida en que el espíritu posee las facultades del entendimiento y de la voluntad, y éstas son el objeto de estudio de la filosofía, se justifica la división de la disciplina en filosofía del entendimiento y en filosofía moral. Por intermedio de la primera procuramos el conocimiento de las operaciones del entendimiento ("Psicolojía Mental o Intelectual") y la determinación de reglas para la dirección de las operaciones intelectuales ("Lójica"); por la segunda se estudian las facultades y operaciones de la voluntad ("Psicolojía Moral") y las reglas para la dirección acertada de los actos voluntarios ("Ética”).

Las tareas de la filosofía, para Bello, quedan delimitadas, pues ésta se ocupará, por una parte, de estudiar y por la otra, de reglamentar lo concerniente al conocimiento de las afecciones que experimentamos, y a los actos que ejecutamos. Afecciones y actos, que a juicio de Bello, remiten o hacen suponer facultades habilitantes que les son propias al alma.

La primera de las tareas que asigna Bello a la filosofía corresponde con la Filosofia del Entendimiento, e intenta sacarla adelante con sus escritos sobre "Psicolojía Mental" y "Lójica", disciplinas fundamentales de la "Ciencia del entendimiento humano" . El filósofo comienza con una investigación sobre el entendimiento

\footnotetext{
Bello, A., Filosofía del Entendimiento, Obras Completas, Santiago de Chile, Edición del Consejo de Instrucción Pública, V.I., 1881, p. 1. Reproducimos los textos respetando la ortografía empleada por el autor.

Id.

Id.

Bello, A Filosofia del Entendimiento, p. 2.

Bello, A. Filosofia del Entendimiento, p. 2.
} 
humano porque su fundamento se halla en el espíritu humano, o alma. Este espíritu está dotado de conciencia y voluntad y, gracias a estas facultades, puede no solo hacerse cargo de sus actos (con limitaciones), sino también, y he aquí el trasfondo del asunto, saber, o hacerse cargo, de lo que le acontece. El espíritu humano obra y padece con conciencia. El espíritu es el depositario de la conciencia y sin la conciencia no hay conocimiento. Las modificaciones, actos o padecimientos, son propias del alma, señala Bello y agrega que son conocidas directa e inmediatamente; esto es, el conocimiento no está fuera del radio de acción del espíritu, pues conciencia y alma son inseparables.

Las modificaciones del espíritu se producen en conexión con fenómenos circunscritos al cuerpo y, especialmente, con procesos del sistema nervioso. Dice Bello:

Fenómenos que pueden consistir en mutaciones mecánicas, físicas, químicas, eléctricas o de la especie que se quiera. Pero estos fenómenos no los percibimos inmediatamente, no tenemos conciencia de ellos, ni llegamos a conocerlos sino mucho más tarde, i aun eso imperfectamente, por medio de investigaciones que ejecutamos con la vista, el tacto i los demás sentidos, de cuyo ministerio nos servimos para investigar las cosas materiales del único modo que no es posible, el cual, según veremos luego, es indirecto i simbólico ${ }^{8}$.

Entonces, el modo de conocimiento respecto a las cosas materiales es "indirecto y simbólico"; pero, ¿a qué se refiere Bello con este par de términos?, ¿qué significa conocer de manera indirecta y simbólica? Digamos, por ahora, que Bello apunta hacia una teoría de la experiencia del mundo externo en la que juega un papel importantísimo la representación. En efecto, para Bello, los sentidos sirven para representarse, mediados por "las sensaciones que intuimos", las "causas remotas, frecuentemente desconocidas" que configuran el objeto de la experiencia. Y es que la conciencia accede, o capta, inmediata y directamente su objeto, pero no se trata de un objeto externo a ella, material. El trabajo de los sentidos está caracterizado por la mediación ${ }^{9}$. Hasta aquí, se puede inferir que Andrés Bello sostiene que los sentidos son instrumentos muy útiles en la investigación de los fenómenos físicos, pero que por sí mismos, dichos instrumentos, no proveen conocimiento. Así las cosas, del mundo material sólo es posible un conocimiento mediado por la interpretación, por su inserción en el reino de lo simbólico. El mundo inerte de la materia, y en esto Bello no se aparta ni un ápice de la tradición metafísica, sólo entra al ámbito del sentido mediante la acción vivificadora (o productora de sentido) del espíritu. Parece, pues, que la idea de representación se hace presente junto con lo simbólico.

La actividad del espíritu o de alma tiene su santo y seña tanto en el auto escrutinio como en el examen de los fenómenos del mundo externo. El examen de sí mismo permite, por analogía, atribuir a los otros seres humanos las facultades que se hallan en el origen de los actos que el alma humana es capaz de ejecutar. Facultad es, dice Bello, "la posibilidad de ejecutar un acto"10; entonces, si existen distintas especies de actos habrá que pensar en distintas facultades del alma o espíritu. Y es que hay una comunión entre acto y facultad en virtud de que "la naturaleza de una facultad

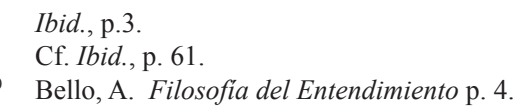


está toda en la naturaleza del acto"11. Desde el punto de vista del lenguaje, facultad y acto son palabras correlativas; y de este modo, Bello pasa de la relación lingüística al terreno de la epistemología, para afincarse en la tesis según la cual un acto del alma existe necesariamente por una facultad o capacidad de la misma, y además contiene la naturaleza del acto. En ese sentido, las facultades, cualesquiera que sean, están indisolublemente estructuradas en la unidad del "yo":

No debemos concebir las facultades espirituales como diferentes órganos particulares del alma; porque en cada una de ellas i en cada uno de sus actos está el alma toda, el yo. El alma que siente es el alma misma que recuerda, que juzga, que raciocina, que desea, que teme, que ama, que aborrece, i, por mas atentamente que ella se contemple a sí misma, no le es posible referir sus varias modificaciones a diferentes porciones o localidades de sí misma. La conciencia nos testifica del modo mas claro la simplicidad o indivisibilidad del alma i su constante identidad consigo misma en todos sus actos ${ }^{12}$.

Entonces, las distintas especies de actos del alma, como ya señaló Bello, remiten a facultades. Y ateniéndose pues, a la clasificación bipartita de entendimiento y voluntad, el filósofo venezolano comienza su investigación tomando como punto de partida el estudio de la percepción, la cual es incluida dentro de la noción de entendimiento y es descrita como, "aquella que mas continuamente ejercitamos i que interviene en el ejercicio de todas las otras"13. Pues bien, la referencia a la percepción como una facultad del entendimiento, ejercitada continuamente e involucrada en las operaciones de otras facultades, resulta capital para entender la teoría de la experiencia en la epistemología desarrollada por Bello.

Desde nuestra perspectiva, la contribución de la percepción al conocimiento del mundo externo, de los fenómenos físicos, aparece en la Filosofía del Entendimiento como un hecho incuestionable. Pero aunque esta certeza constituya un punto de partida, no basta afirmar que para Bello la percepción es fuente primordial del conocimiento por experiencia. Es necesario dilucidar cómo o de qué maneras la percepción funciona como una facultad involucrada en la elaboración de la experiencia y cuáles son los argumentos que este filósofo presenta para sostener esta tesis.

La tarea central de este estudio sobre la Filosofía del Entendimiento atiende al examen de las siguientes cuestiones: ¿Qué es la percepción?, ¿qué es la sensación?, ¿cuáles son los elementos dentro del proceso de la percepción?, ¿cuáles son los tipos de percepción que identifica Bello y cuáles son sus características específicas?, por último, ¿cómo entiende y relaciona Bello conciencia y percepción?

11 Id.

12 Bello, A. Filosofía del Entendimiento, p. 4. Estos juicios de Bello recuerdan lo dicho por Kant en torno a la unidad trascendental de la apercepción, a inicios de parágrafo 16 de "Deducción trascendental". Cf. KANT, I., Crítica de la razón pura, Madrid, Alfaguara, 2004. El "yo pienso" planteado por Kant garantiza la unidad de todas las representaciones. Bello no agrega el "pienso", pero la función del yo en su teoría epistemológica atiende a un problema similar al enfrentado por Kant. De igual manera, las cualidades y los actos del alma que enumera guardan ciertas similitudes con la respuesta cartesiana planteada en la "Segunda meditación", y que a su vez está relacionada con la pregunta “¿qué soy?”. Cf. DESCARTES, R., Meditaciones metafísicas, en Descartes, Madrid, Gredos, 2011, p.173. Véase la cita con nota al pie 75 de este ensayo, asimismo, el análisis y tratamiento que se le da a este tópico en el apartado VI.

13 Bello, A., Filosofía del Entendimiento, p.5. 


\section{Qué es la percepción}

La afirmación: "no hay percepción en la que no intervenga la conciencia, ni percepción sensitiva en la que no haya una sensación que simbolice una cualidad o estado corpóreo que las excite"14, despeja dos cuestiones importantes, a saber, que percibir es un acto consciente y como tal disponible para el tratamiento reflexivo; también, que la percepción puede ser o no sensitiva, pero en el último caso la sensación es un elemento esencial que en tanto acto consciente remite a causas materiales. Aunque Bello no se anima a definirla, sí afirma que:

La percepción es, en jeneral, un acto en que el alma adquiere el conocimiento de cierta cualidad o estado particular de un objeto, en virtud de cierta acción que el objeto ejerce actualmente en ella. No tratamos de definir la percepción, sino solo de señalarla o de manifestar las circunstancias en que esta facultad se realiza ${ }^{15}$.

Conviene hacer notar que el filósofo sostiene que el alma adquiere el conocimiento de alguna cualidad o estado de un objeto en determinadas condiciones; ciertamente, el objeto actúa sobre el alma, pero que ésta realice una adquisición de tipo cognoscitivo significa que hay una interacción, o una transacción, entre el alma y el objeto. El alma no permanece pasiva y entonces no trata Bello la cuestión como una simple mecánica en la que una cosa, siguiendo la metáfora ya conocida, deja una marca en una tabla de cera o un medio simplemente impresionable. Con esta primera aproximación a la noción de percepción, Bello nos hace pensar que el acto de la percepción no es un asunto que sólo compete a la intervención de los sentidos y que deja de lados los procesos intelectivos. Por supuesto, puede que en este pasaje use en un sentido un tanto laxo el término conocimiento. Habrá que ver.

Si pensamos en la percepción como un proceso que implica la adquisición de la conciencia de un objeto y de un estado particular en la que éste se encuentra, no vemos el por qué haya que agregarle la actividad intelectiva. Es decir, si percibir significa tener presente un algo que me hace frente, que me afecta sensorialmente, no parece necesario afirmar que en ese acto nos apropiamos conceptual y discursivamente de las cualidades y el estado del objeto. Pero por otra parte, las cosas en el mundo tienen, según Bello, un diseño con cualidades y capacidades que producen efectos en las capacidades perceptivas del alma. El caraqueño, incluso, sugiere cierto tipo de actividad objetual:

Entre las acciones de los objetos sobre el alma y las cualidades de los objetos, hai la misma correlación que los actos y las facultades del alma o de un ajente cualquiera. Así como todo acto supone en el ajente la facultad o poder de desarrollarlo, así cada una de las acciones particulares de un objeto sobre el alma, supone en él una cualidad particular, que verdaderamente no es otra cosa que el poder o facultad de desarrollar esa acción. Los objetos se nos dan a conocer por sus cualidades, o en otros términos, por las diferentes acciones que corresponden a esas cualidades $i$ en que esas cualidades se desarrollan ${ }^{16}$.

\footnotetext{
Ibid., p.16.

Bello, A., Filosofia del Entendimiento, p. 16

Bello, A., Filosofía del Entendimiento, p. 7.
} 
Una cuestión problemática en estas aseveraciones es el guiño del autor a las doctrinas del realismo y del empirismo; por supuesto, es problemático en la medida en que no se tiene claro la clase de compromiso y a qué tipo de realismo hacía referencia Bello. Del mismo modo ocurre con el empirismo, a pesar de que afirma la existencia de propiedades objetuales que afectan el alma de ciertas maneras, no dice, todavía, que de ellas se generen ideas y estricto conocimiento. Los objetos nos afectan de determinadas maneras y se nos presentan en ciertas condiciones particulares en virtud, como hemos dicho antes, de un diseño que es propio de una realidad ajena a los poderes del sujeto. Entonces, así como el alma tiene su diseño, que Bello llama facultades, las cosas también tienen el suyo. De esta manera, el acto de la percepción se produce no sólo porque el alma tiene capacidades para tales fines sino porque los objetos también las tienen ${ }^{17} \mathrm{y}$, entonces, el acto perceptivo obedece a un ensamblaje y una sincronización entre alma y objeto. Ensamblaje y sincronización, por cuanto sugiere Bello una doble dirección de ajuste que va del alma al objeto y del objeto al alma, contando para ello con un marco espacio temporal. La explicación de la percepción se entiende, entonces, como un acto en cuyo núcleo se encuentran dos actividades, la del sujeto y la del objeto: "Los objetos se nos dan a conocer por sus cualidades, o en otros términos, por las diferentes acciones que corresponden a esas cualidades i en que esas cualidades se desarrollan"18. Asume Bello una perspectiva realista sui generis, a decir de Rafael García Torres, pero que se torna valiosa en tanto "supera los males causados por la lectura escéptica de Hume, y precariamente racionalista de Locke"19.

En atención al final del párrafo precedente. Conviene un examen más detallado de la posición de Andrés Bello sobre las relaciones entre alma y objeto. En "Examen sobre la teoría de las percepciones sensitivas externas, según la escuela escocesa"20, Bello reflexiona sobre las doctrinas de John Locke, George Berkeley y Thomas Reid en torno a la percepción sensitiva. En estas críticas entran en juego las distinciones entre cualidades primarias y secundarias, así como su relación con las ideas. Respecto de la doctrina de Locke dice que acierta en cuanto coloca entre las cualidades primarias a la extensión, la dureza, la elasticidad y otras cualidades complejas, pero le acusa de no justificar su afirmación según la cual las ideas de esas cualidades y las cualidades mismas de los cuerpos están en una relación de semejanza; más todavía, señala que no explica ni argumenta esta otra afirmación: que los "modelos o prototipos [de tales ideas] existen en los cuerpos mismos" respecto a lo anterior, Locke deja un cabo suelto, a juicio de Bello, pues no ofrece ni evidencias ni argumento para hacernos una idea de hasta qué punto puede haber

17 Respecto a estos planteamientos de Andrés Bello dice Rafael García que: "La actividad de los objetos consistiría en el impacto que sus cualidades tienen sobre la mente (o el alma, en la terminología de Bello). Nótese que la tesis del filósofo caraqueño se desplaza del orden epistemológico al orden ontológico, en el sentido de que lo percibido está efectivamente en el objeto, pues en caso contrario no se percibiría”. García Torres, R., "Anotaciones en torno a la teoría de la percepción en Andrés Bello: una lectura desde el modelo empirista inglés", en Miranda, Bolivar y Bello: tres tiempos del pensar latinoamericano, Caracas, Fundación Konrad Adenauer Stiftung-UCAB, 2007, p.301.

18 Bello, A., Filosofía del Entendimiento, p. 7.

19 García Torres, R., "Anotaciones en torno a la teoría de la percepción en Andrés Bello: una lectura desde el modelo empirista inglés", p. 301.

20 Cf. Bello, A., Filosofia del Entendimiento, p. 267 y ss.

21 Ibid., p. 270. 
semejanza entre "afecciones espirituales y afecciones corpóreas"22. Seguido, Bello expone la posición de Berkeley. Aquí expone que éste niega rotundamente cualquier relación epistemológica entre ideas y cosas materiales. De mismo modo, explica que para Berkeley las ideas simplemente están en conexión con otras ideas y que niega la distinción efectiva entre cualidades primarias y secundarias ${ }^{23}$. La tercera doctrina en Crítica es la Reid. Este filósofo distingue y separa sensación y percepción, de manera tal que no habría conexión alguna entre ellas ${ }^{24}$. Eso sí, habría una tendencia errónea a conectarlas debido a que suceden una después de otra. Bello no lo dice en su crítica, pero diríamos nosotros que al afirmar que se hallan en conexión estaríamos incurriendo en la falacia de causa falsa. Bello señala que la doctrina sobre la percepción de Thomas Reid adolece de inconsistencias: "la percepción es una intuición inmediata del objeto corpóreo, i nace del alma a consecuencia de la sensación, aunque nada tiene que ver con ella; de manera que la impresión orgánica, la sensación i la percepción nada tiene que ver con ella" ${ }^{25}$. Andrés Bello se opone abiertamente a esta doctrina sobre la percepción sensitiva de Reid argumentando que es imposible negar que existe una conexión, él evidente, entre la impresión orgánica, la sensación y la percepción sensitiva ${ }^{26}$. Agrega, además, que Reid está en un desacierto al sostener que no hay conexión entre sensación y percepción sensitiva, porque la sensación es constitutiva de la percepción sensitiva y no un signo como afirma $\operatorname{Reid}^{27}$. Con la crítica a la doctrina de la percepción sensitiva de Thomas Reid, y la toma de distancia de las doctrinas de Locke y Berkeley, Andrés Bello reafirma su tesis de que distintos tipos de sensación sugieren distintas ideas dentro de un proceso de maduración propio del ser humano ${ }^{28}$.

\section{Qué es la sensación}

Las cosas, por su constitución material, tienen en su poder la capacidad de producir sensaciones en los seres dotados de una constitución sensible, porque afectan los sentidos: "Se llama ser material o materia todo lo que es capaz de producir sensación" 29. Según Bello, esas afecciones, en cuanto sensaciones, son productoras de conocimiento. Si está involucrado un solo sentido en la exploración de un ser (como el olor de un clavel, según el ejemplo que usa el filósofo), entonces se trata, en principio, de un conocimiento oscuro y elemental ${ }^{30}$; pero si luego se involucran otros sentidos y con ello otras sensaciones respecto a ese mismo ser, entonces resulta un objeto complejo que viene a ser mejor conocido que en el anterior estadio en el que solo estaba involucrado un sentido y un solo tipo de sensación.

A mayor número de sensaciones elementales conjugadas en torno a la exploración de un ser, menor oscuridad cognoscitiva; en este caso, la complejidad sensorial

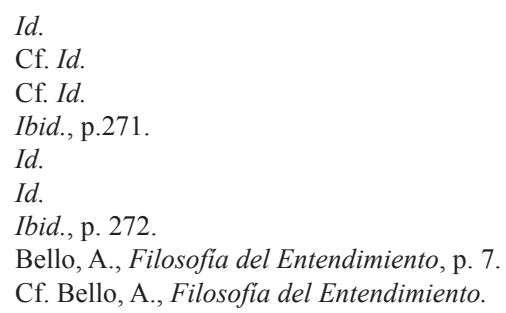


es factor de delineamiento objetual. Pero Bello no se detiene en este punto, sino que afirma: "Este conjunto de sensaciones por cuyo medio conocemos un objeto complejo, forma una idea compleja" ${ }^{31}$. Entonces, se forman ideas complejas a partir de la combinación de sensaciones sobre un mismo ser material. Sensación no es en este caso una afección puramente subjetiva, sino que es producto de la interacción con un ser material. Vista así, la sensación es un tipo de percepción vinculada al conocimiento; repárese en la diferencia con Kant, por ejemplo, para quien la sensación sí es una percepción simple y llanamente subjetiva ${ }^{32}$. Pero si encontramos una importante divergencia con respecto a Kant, también encontramos algunas aproximaciones al empirismo de Locke y de Hume, especialmente con respecto a la doctrina de que las ideas se derivan de las sensaciones ${ }^{33}$. Ahora, para Hume, las sensaciones, entendidas como impresiones, producen ideas simples. Luego, la mente hace combinaciones con distintas ideas simples que producen las complejas. Una diferencia notable con el empirismo inglés es que en Bello las ideas complejas provienen de percepciones sensitivas complejas, pero no de forma mecánica.

La producción de ideas no se da de manera mecánica porque el alma no es un ser inerte en la doctrina epistemológica bellista, de allí que hablemos de acoplamiento y sincronía. La aplicación de uno de los sentidos al examen de un ser material produce un tipo de sensación, y ésta, a su vez, un conocimiento oscuro y parcial, según Bello (diríamos, sin ser fieles completamente al lenguaje cartesiano, que se trataría de una idea con poca claridad y distinción); pero cuando se aplican dos o más sentidos a la exploración de ese mismo ser, entonces, aparecerán involucrados distintos tipos de sensaciones y con ello una idea compleja, cuyos rasgos resultarían más claros y distintos que los producidos por uno solo. En la duración del acto, en su actualidad, se produce la idea que permanecerá en el alma. La idea será, entonces, "percepción renovada, recuerdo, idea". ${ }^{34}$

¿Por qué hemos dicho que la producción de ideas no es un acto mecánico?, ¿por qué no se pasa directamente del impacto sensorial a la idea como si ésta estuviera contenida en la sensación? Cuando Bello explica esta doctrina por intermedio del ejemplo del olor del clavel dice que "el alma, la conciencia, el yo, no percibe directamente el olor del clavel; lo que percibe directamente es una modificación suya propia, que para ella no tiene relación ninguna con un ser distinto de ella". ${ }^{35}$ Aunque pensamos en un encuentro concordante entre alma y cosa, no hay una sola dirección de ajuste. No puede decirse que Bello sostenga que una impresión de las cosas, por intermedio de los sentidos, sea la causa directa de las ideas en el alma, pero hay cierto poder en la materia para provocar los procesos perceptivos y cognitivos que se dan lugar en el alma. Si el alma no percibe directamente el olor del clavel es porque reelabora el material que recibe por intermedio de los sentidos.

La sensación no se equipara, en Andrés Bello, a un simple proceso orgánico o fisiológico, pues afirma que: "cuando cierta modificación particular es producida actualmente en el alma por la acción de un ser material, a que atribuimos en consecuencia una cualidad, damos a esa modificación del alma el nombre de

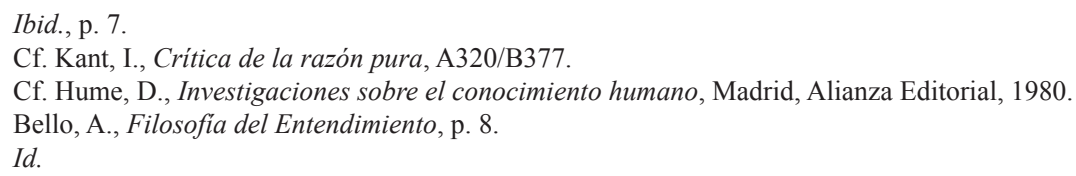


sensación" ${ }^{\prime 3}$. Debe notarse que las funciones fisiológicas y netamente orgánicas que conforman la primera línea de contacto con los objetos materiales, y por tanto el punto de partida para las diversas modificaciones particulares, aunque necesarias, no son suficientes para la producción de las sensaciones. La sensación, así parece inferirse de la doctrina de Bello, es un resultado definido por la actividad del alma porque las asimila a un ámbito epistémico. En este sentido, y como punto clave, la referencia a la atribución de cualidad apunta a una intervención discursivo-reflexiva, probablemente de muy bajo nivel ${ }^{37}$.

Entonces, aunque estrechamente vinculada con procesos orgánicos y objetos materiales, la sensación es una especie de cuasi-percepción. La sensación, como apuntamos antes, es una modificación particular que se produce actualmente en el alma por la acción de un ser material ${ }^{38}$; un estado corporal, particular, que por intermedio de los nervios y el cerebro produce una afección que el alma asimila y procesa. Sin embargo, Bello distingue dos casos, a saber: cuando un objeto externo produce afecciones en el organismo, y cuando es el mismo organismo el que produce una sensación en virtud de modificaciones propias. En el primero hay una mediación entre el objeto material y el alma, esa mediación es orgánica; en el segundo caso, dice Bello, no hay mediación alguna porque es una relación entre el organismo y el alma. Conviene no pasar por alto esta distinción; que no hay mediación debe entenderse como un proceso interno en el que no hay un objeto ajeno al cuerpo, pero en modo alguno como una ausencia de procesos racionales y lingüísticos, pues aquí también se atribuye un estado: "fatiga". La atribución y auto atribución de estados sólo es posible en un ser con competencias racionales y lingüísticas, no es un asunto de padecimientos.

La sensación es un tipo de cuasi-percepción que permite los vínculos entre el evento físico (sea provocado por un objeto externo, sea por modificación orgánica sin intervención externa) y la conciencia; pero estamos ante un asunto complicado porque, para Bello, la conciencia, el alma, nunca accede directamente al estado o cualidad material: "Pero ni en uno ni en otro la cualidad o estado es un objeto para la conciencia; lo que la conciencia percibe directamente es la sensación; la cual se convierte así en una percepción o conocimiento de cierta cualidad o estado material" ${ }^{39}$. Esta es la complicación, el caraqueño sostiene que el paso de la sensación a la percepción ocurre cuando interviene la conciencia: "una afección particular en el alma; afección que es también sensación, i que contemplada por la conciencia, constituye una percepción de ese estado corpóreo" ${ }^{40}$. La contemplación consciente marca la diferencia entre una simple afección sensorial y una percepción. Sensación y percepción coexisten en un determinado instante cuando ocurren el evento sensorial y el procesamiento del mismo por intervención de la conciencia. De allí que señale, sin apartarse de la tradición empirista inglesa: "Mientras esa afección

$36 \quad I d$.

37 No acontecería en este punto una reflexión muy elaborada, pero la atribución de una cualidad a una afección requeriría de dominio lingüístico y de una mínima reflexión. Este punto nos hace pensar en las tesis de Wilfrid Sellars, especialmente las expuestas en: "Empirismo y la filosofía de lo mental" en: Ciencia, percepción y realidad, Madrid, Tecnos, 1971. Si seguimos esta línea interpretativa, ni siquiera la sensación no sería algo "dado", inmediato. Estaría inmersa en el ámbito del sentido y por ello se le atribuye alguna cualidad.

38 Cf. Bello, A., Filosofía del Entendimiento, p. 9.

39 Id.

$40 \quad$ Ibid., p. 8. 
espiritual coexiste con el estado corpóreo que la produce, tenemos una percepción actual; cuando esta termina, lo que de dicha afección queda o resucita después en el alma, es una percepción renovada, un recuerdo, una idea"41. La conciencia garantiza el paso de una percepción actual a una idea o percepción renovada, y es ella misma quien la actualiza sacándola de la memoria.

\section{Percepción y sensación}

Pero, ¿cómo se conectan sensación y percepción?, ¿cómo se da el paso de la una a la otra? La clave para comprender la conexión entre sensación y percepción se halla en la intervención de la conciencia, porque no podríamos siquiera hablar de sensación sin competencias racionales y conceptuales. Pero, ¿por qué decimos que la sensación es una cuasi-percepción? Porque Bello dice que: "Tanto la sensación producida por el organismo como la sensación producida por un ser material extraño, simbolizan cualidades"42. ¿Qué significa que ambos tipos de sensación simbolizan cualidades? La sensación no es simple impacto o simple modificación orgánica, sino un acontecimiento humano moldeado por el gálibo de la experiencia. Una conciencia experimentada y conceptualmente estructurada se mueve en un universo simbólico, pero como no hay conciencia sin cuerpo, entonces lo que afecte al cuerpo será susceptible de caer bajo la influencia de la conciencia y ser contemplado en clave simbólica. Que la sensación es un acto del alma, consciente, inserto en el ámbito del sentido, se halla dicho claramente en Filosofía del Entendimiento: "El alma percibe la sensación en sí misma de la misma manera que percibe en sí misma sus juicios, deseos, voliciones i otras varias modificaciones suyas que no son sensaciones"43. Pero, ¿qué significa que el alma percibe?

Bello distingue, lo hemos señalado, las esferas de las sensaciones y de los procesos y modificaciones orgánicas. De allí que sensación e impresión orgánica sean "dos cosas enteramente distintas y separadas", pues la sensación es propia del alma y la impresión orgánica de la materia ${ }^{44}$. ¿Por qué retomamos este asunto?, pues porque esta dualidad nos permite sostener nuestra tesis de que la sensación, en tanto acto del alma, es un elemento de la percepción, aunque sólo de la percepción sensitiva ${ }^{45} \mathrm{y}$, por tanto, con una carga, aunque sea mínima, de sentido.

Bello dice que

El alma percibe en su propio ser intuitiva, esto es, inmediata i directamente, la sensación i la refiere a la impresión orgánica como a su causa próxima, representado o simbolizando esta causa por medio de la sensación i concibiendo tantas diferencias i variedades en el órgano, cuantas son las que percibe en la sensación"46.

¿Cómo el alma percibe intuitiva e inmediatamente?, en tanto no es menester la intervención de la observación por intermedio de los sentidos, sino que percibe y

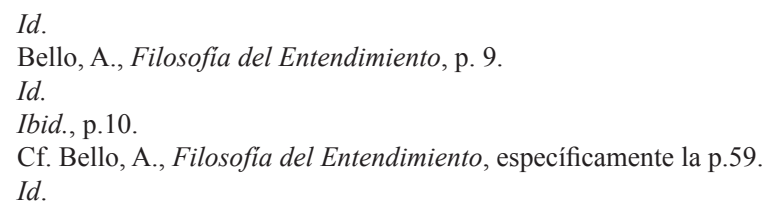


cataloga de acuerdo, digamos, a la legalidad que le es propia. El alma relaciona la sensación a una causa orgánica, la representa y simboliza, por las capacidades conceptuales que posee. Esa capacidad de representar y de darse cuenta de qué está sucediendo la identificamos con la facultad de conceptualizar. No tenemos dudas de que en la epistemología de Bello, representar requiere capacidades de conceptualización y, por tanto, de dominio lingüístico. Entonces, inmediatez significa sólo la no intervención de la observación sensorial de las modificaciones orgánicas, pero en modo alguno la ausencia de las mediaciones conceptual y lingüística.

Si la sensación, en cuanto elaboración del alma, no se halla vinculada de alguna manera a capacidades de conceptualización, entonces quedaría en una especie de limbo epistemológico y la referencia a ella en el esfuerzo por explicar la percepción sería poco menos que inútil. Hemos dicho que la sensación es una cuasi-percepción, porque no se reduce a lo orgánico, porque es una función del alma que está involucrada en la elaboración de la percepción. Tiene una causa próxima que es la impresión orgánica, pero la vinculación consciente o referencia a dicha causa corresponde al terreno de las funciones judicativas. Es un juicio, pues, lo que "agregado a la sensación i a la intuición de la sensación, constituye verdaderamente la percepción de un estado orgánico o de una cualidad material cualquiera" ${ }^{47}$. En la percepción, las capacidades conceptuales se ponen en pleno funcionamiento. Ni sensación ni percepción son procesos y productos que se reduzcan a lo orgánico y fisiológico.

\section{Variedades de la percepción}

Hay dos tipos generales de percepción, según Andrés Bello; a saber, las percepciones intuitivas y las sensitivas o representativas, por las primeras el alma percibe en sí misma sus modificaciones, por las segundas conocemos sobre los objetos materiales que nos afectan y sobre sus estados; las percepciones sensitivas también son responsables de las representaciones sobre los distintos estados de nuestro organismo ${ }^{48}$. Hay algo más al respecto y es que las percepciones intuitivas se encuentran en el origen o base de formación de las percepciones sensitivas o representativas ${ }^{49}$. Sin conciencia de lo que ocurre en nosotros mismos, de las modificaciones experimentadas en nuestra alma, no es posible volcarse a la representación de los objetos físicos. Se infiere de lo planteado aquí, que la dirección de ajuste de la percepción va del alma, o la conciencia, a los cambios físicos experimentados por el cuerpo, como causa próxima, y al objeto externo como causa remota. En fin, lo que acontece en el alma sólo es conocido por el alma misma; es la conciencia de sí misma. Tenemos, según Bello, un acceso privilegiado a nuestra propia constitución anímica y sus procesos.

Con las representaciones intuitivas Bello introduce la noción de intuición; pero lo que quiera que ésta sea para el filósofo, no es algo expresado con meridiana claridad por él que la define, como en este caso, via negationis: "La intuición no es una sensación" 50 . O en este otro caso en el que dice que, "la existencia de la intuición es evidente; su naturaleza, inescrutable; como la naturaleza de la sensación i de todas

\footnotetext{
Ibid., p.11.

Ibid., p.11.

Id.

Ibid., p. 25.
} 
las otras modificaciones elementales del alma"51. Veamos ahora cómo el alma es aquí el fundamento de la percepción. Dice el caraqueño que en el proceso de percepción nuestra alma obra una modificación en sí misma, ocurre una modificación sobre otra; pero lo destacable es el acto de contemplación y esa contemplación es la que él llama intuición ${ }^{52}$. Pero esta intuición no es en sí misma la percepción intuitiva, pues es necesario que el alma, en un proceso interno de desdoblamiento especular, refiera a sí misma la primera modificación que ha experimentado $\mathrm{y}$, al combinar "intuición i referencia de la intuición" 53 , el alma forma la auténtica percepción intuitiva. Se afirma aquí la autonomía de los procesos de pensamiento; el alma tiene el poder de percibirse a sí misma y tiene una autonomía de tratamiento objetual. La percepción intuitiva se presenta a la conciencia, por una parte, en un rol pasivo, en cuanto contempla la modificación objeto; por otra parte, se manifiesta en un rol activo en cuanto afirma la identidad entre el objeto contemplado y el sujeto que contempla el objeto $^{54}$. La percepción intuitiva representa a la conciencia en su actividad y procesos esencialmente internos.

Según Bello, la percepción sensitiva se caracteriza por la afección orgánica, por la presencia del "elemento material"; por "una sensación particular" que se corresponde con la impresión orgánica; por una "intuición de la sensación" y, por último, por una referencia de la sensación al órgano impresionado ${ }^{55}$. Conviene resaltar que la percepción sensitiva, al igual que la intuitiva, no es un acto simple. La percepción es un proceso cuya secuencia y partes definen los tipos o variedades. Sin embargo, en la percepción sensitiva es el alma quien produce la percepción una vez afectada orgánicamente $y$, además, la percepción intuitiva se encuentra en su base ${ }^{56}$. La diferencia es que más allá de la necesaria presencia de la percepción intuitiva es esencial la sensación, cuya presencia es accidental en la percepción intuitiva.

Al respecto, Bello insiste en discriminar entre los elementos que pertenecen al ámbito de la materia y los que pertenecen al del alma. Tanto la agencia corpórea sobre los órganos como la impresión orgánica misma entran en el primer dominio que hemos señalado; en cambio, sensación particular, conciencia de la sensación y referencia de la sensación a la causa remota, pertenecen al segundo dominio. Las percepciones sensitivas pueden ser internas y externas.

En la percepción sensitiva interna la afección se produce sin concurso de un agente externo que produzca la impresión orgánica; aquí la modificación orgánica acompaña a la sensación, la intuición de la sensación y la referencia de la sensación; referencia que se hace a una causa próxima. Un ejemplo de este tipo lo encontramos en la experimentación de un dolor sin que haya sido causado por una gente exterior. Se la adjetiva interna, dice Bello, porque "sus objetos están circunscritos al cuerpo" y "simbolizan cualidades o estados del organismo que no pueden concebirse sino en algún cuerpo animado, como el hambre, el sueño, el cansancio i todos los placeres y dolores que referimos a los órganos" ${ }^{57}$. De esto último se deriva que Bello hable de sentido del hambre, sentido del sueño, y así por el estilo, para denotar que es el alma misma la que percibe estas modificaciones en su propio ser.

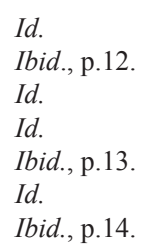


En la percepción sensitiva externa es necesaria la referencia a una causa remota, instanciada de ordinario ${ }^{58}$ en "un ajente distinto a nuestro propio cuerpo" 59 y así, en lugar de cuatro elementos, como en la percepción sensitiva interna, tenemos cinco. Bello explica este tipo de percepción sensitiva echando mano de la percepción visual. Ver algo ${ }^{60}$ requiere que un objeto externo afecte los órganos que componen el sentido de la vista. Los cinco sentidos y sus órganos están en la base de producción de ciertos tipos de sensaciones como las visuales, gustativas, olfativas, táctiles y auditivas. Para este filósofo, la sensación, componente esencial de las percepciones sensitivas, está en el lugar de, o "representa", una cualidad o un estado material, y la referencia al objeto de la percepción sensitiva consiste en una relación de causalidad; la sensación es un efecto de la cualidad o estado material ${ }^{61}$.

Para Bello, si percibir es una cualidad del alma también lo es sentir. No son los órganos los que sienten, sino el alma:

Observaremos también que sentir, en el significado de experimentar sensaciones, es propio i privativo del alma. Los sentidos tienen, pues, su asiento en el alma, son el alma misma aplicada a los objetos corpóreos, i debemos rechazar la preocupación vulgar que los confunde con los órganos por cuyo medio se ejercitan. El alma es propiamente quien ve, oye, huele, gusta, toca. Ella i no el cuerpo es quien siente fatiga, sueño, hambre, etc. Los órganos son meros instrumentos de la percepción. Decir que los ojos ven es hablar metafóricamente, es según observa Reed, como decir que un telescopio ve. La mano toca como un cuerpo inanimado toca a otro; tocar, en el sentido de percibir por el tacto, es propio i privativo del alma ${ }^{62}$.

Los órganos son instrumentos al servicio del alma y son importantes para los propósitos de hacer contacto, experimentar y explorar el mundo de las cosas materiales; no obstante, las facultades de sentir y percibir están más allá de los órganos sensoriales. Así, queda claro que no es el ojo quien ve, ni la nariz quien huele, ni la lengua quien gusta, etc. De allí la insistencia en las expresiones propio y privativo; el alma es la única facultada para sentir y percibir.

Sentir y percibir involucran el poder de significar y es el alma la única facultada para la producción del significado. De esta manera, el ser humano se mueve en un mundo simbólico, y así el contacto con la materia está siempre mediado por las capacidades de significación propias del alma. Por supuesto, la inmediatez sólo se produce cuando el alma se intuye a sí misma. El mundo de la materia es para Bello una especie de "cosa en sí", si lo decimos con el lenguaje kantiano: "Lo que son la materia i las cualidades materiales en sí mismas i no meramente como causas de sensaciones, no lo sabemos ni es accesible este conocimiento a las facultades mentales de que estamos dotados"63, lo cual quiere decir que, o bien la materia

58 De ordinario, siguiendo al mismo Bello, porque puede suceder, aunque no sea lo común, que una parte del cuerpo actúe sobre otras partes del mismo y los efectos sean equiparables al de los agentes materiales genuinamente externos.

59 Bello, A., Filosofía del entendimiento, p.14.

60 En el ejemplo de Bello queda claro que las alucinaciones no cuentan como un caso estricto de percepción visual. Véase, Bello, A., Filosofía del Entendimiento, p. 14.

61 Ibid., p.16.

62 Ibid., pp. 17-18.

63 Ibid., p.19. 
presenta una barrea infranqueable para impedir el poder de penetración de las potencias del espíritu, o bien el espíritu sólo conoce lo que él mismo configura en clave simbólica. Si ocurre esto último, entonces debemos rechazar nuestra inicial consideración de un ensamblaje entre alma y mundo material en el cual cierto diseño del mundo estimula las capacidades del alma para que active sus capacidades de significación. Por supuesto, que la materia no permita la penetración en su intimidad no conduce necesariamente a excluirla del juego de la producción del significado debido a que Bello admite una conexión cognoscitiva, aunque indirecta, entre ella y las sensaciones: "no percibimos jamás directamente las modificaciones de la materia; solo las percibimos representativamente por medio de las sensaciones que ella produce en el alma"64. Con esta interpretación de las relaciones entre alma y materia se puede evadir el camino que lleva directamente a un callejón sin salida epistemológico, a saber, el de un alma que sólo conoce lo que ella misma produce; y el roce del espíritu con el mundo externo no quedaría en entredicho.

Bello asume la teoría de la representación como la doctrina que explica la actividad perceptiva y de conocimiento en los seres humanos, pero esta elección trae aparejada algunas dificultades. Las imágenes no son las cosas, son más bien el resultado del juego especular del alma o del espíritu. Según el venezolano, nos movemos en la representación, se trata de imágenes que están en lugar de las cosas y no las cosas mismas. De allí que sostenga que la memoria, si reproduce o actualiza las percepciones pasadas en el mismo orden en que se sucedieron, se denomina recuerdo; pero si las actualiza combinándolas en forma distinta a como el alma las percibió inicialmente, se les llama imaginación. Y hay aún más: las ideas presentes en el "juicio seguro de la realidad de los objetos" 65 constituyen el conocimiento. Si nos atenemos a la hipótesis según la cual el alma no tiene ningún contacto con el mundo material, entonces es imposible salvar el conocimiento como juicio seguro de la realidad de los objetos, porque al preguntar por tal o cuál realidad no podríamos apelar a ningún indicio del mundo externo. Aun así, Bello pone muy difícil el tránsito por los senderos del realismo epistemológico.

Ya se ha examinado, en líneas anteriores, que al percibir los objetos materiales no penetramos en su ser esencial, lo que en sí mismo queda vedado para el espíritu y por tanto para el conocimiento ${ }^{66}$. Sin embargo, cuando el alma es objeto de sí misma, Bello declara que se trata de una percepción inmediata y fundante:

Que el alma tiene la facultad de percibir lo que pasa en ella es una cosa tan obvia, que parece imposible se haya puesto alguna vez en duda. Sin esta facultad, ¿cómo habría existido jamás la Psicolojía, la ciencia del alma? Pero no solo esta ciencia, ninguna otra, el lenguaje mismo, no hubiera podido existir. Es de total necesidad percibir nuestros pensamientos para poder expresarlos ${ }^{67}$.

Dicho de otro modo, significa que el alma tiene como atributo una intuición fundante del conocimiento y del lenguaje; más todavía, de toda ciencia como expresión acabada de la actividad inteligente del alma. Es condición necesaria que

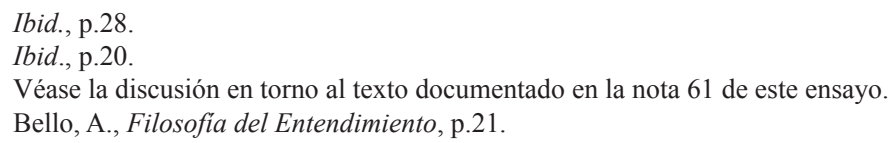


el alma sepa de sí misma y de lo que en ella sucede para que haya conocimiento. Asunto polémico, éste, a tal punto que Bello cuestiona a Thomas Brown ${ }^{68}$ por afirmar como equivalentes las expresiones "tengo conciencia de una sensación" y "tengo una sensación", porque para el caraqueño, en absoluto lo son, pues sostiene que con la primera expresión es evidente que se es consciente de la propia actividad de la conciencia, en tanto que con la segunda expresión sólo se evidencia la conciencia de la sensación ${ }^{69}$. De acuerdo con Bello, el alma llega, entonces, a saber de sí misma y del objeto, al mismo tiempo que enfrenta los fenómenos y, además, puede experimentar al mismo tiempo muchísimas afecciones. Con esta afirmación sigue haciendo frente a las objeciones de Brown, en este caso a su señalamiento de la posibilidad de que el alma pueda sentir y percibir que siente al mismo tiempo. Dice Bello, que aunque el alma fije la atención en uno de los diversos estados que experimente en un instante concreto, no implica que los otros estados coexistentes no estén sucediéndose ${ }^{70}$. Entonces, la vivacidad y fuerza de una percepción está directamente relacionada con la capacidades del alma, pues es ésta la que "ve, oye, huele, gusta, toca" ciertamente, el diseño de los objetos tiene su parte y los órganos la suya, no puede olvidarse entonces que la configuración de la percepción es asunto del alma ${ }^{72}$, y es la conciencia la que fija su atención y hace más nítido uno de entre muchos estados que experimente el alma, lo que Bello llama, "percepciones vivas, atentas"73.

Como en el alma reside el poder de percibir, entonces no resulta extraño en absoluto que aparte de experimentar distintos estados, que son las percepciones actuales, los almacene y los reproduzca por intermedio de una facultad como la memoria, esto es, a través de operaciones tales como recuerdo e imaginación que dan lugar a la idea, lo que en conjunto vendría a ser un tipo de percepción renovada en el alma. Las ideas, en cuanto son imágenes de las percepciones actuales, también son la base de la construcción del conocimiento, pues son imprescindibles en la formulación del "juicio seguro de la realidad de los objetos"74. Sin el poder de almacenaje y reproducción de las percepciones, no habría ideas, y sin ellas tampoco conocimiento.

\section{Unidad primigenia y multiplicidad}

Por cuanto es en la psique en donde ubica Bello el asiento de toda la actividad consciente y, por cuanto es ésta la causa del conocimiento y del lenguaje, la filosofía del entendimiento no puede eludir su estudio. Así, la psicología como disciplina encargada del estudio del alma (o espíritu) se propone indagar sobre esta parte activa que hace de un ser como el humano algo que está más allá del simple mecanismo y, por tanto, irreductible a la pura extensión. Unidad y multiplicidad se conjugan en esta

\footnotetext{
Filósofo escocés de la escuela del sentido común, discípulo de Dugald Steward.

Cf. Bello, A., Filosofia del Entendimiento, p.25.

Cf. Ibid., p.23.

Ibid., p. 18.

"Así la conciencia es la que da el tipo primitivo de las relaciones de identidad, continuidad i unidad; tipo de que después nos servimos como de un signo, para representarnos todo lo que llamamos idéntico, continuo i uno". Bello, A., Filosofia del Entendimiento, p. 26.

73 Ibid., p. 25 .

$74 \quad$ Ibid., p. 20.
} 
búsqueda de fundamento para las operaciones del conocimiento; por supuesto, que en nada resulta admirable si se toma en cuenta que el juego entre lo uno y lo múltiple es una constante en la reflexión filosófica desde sus inicios. Sin embargo, importa, y mucho, tener en cuenta que Andrés Bello se adentra en este añejo y escabroso tema desde una perspectiva que va de lo epistemológico a lo ontológico y viceversa, pues la percepción y todo acto de conocimiento implica la tensión entre lo uno de la idea y lo múltiple de la materia, tensión que busca resolverse, o, ¿quizá aliviarse?, con el establecimiento del unum versus alia.

La inclinación a la uniformidad, o el afán por establecer continentes cognoscitivos, se hallarían en el alma, pues por cuanto ella es en sí misma unidad, puede producir la idea que es la base del conocimiento. Comparativamente, ocurriría entre el entendimiento humano y el conocimiento una relación causal como las expuestas tradicionalmente en la metafísica. En el efecto, el conocimiento, se encuentran las huellas y características de la causa, el alma. La conciencia no hace a la multiplicidad unidad en cuanto a su existencia física, pero sí la hace en cuanto la convierte en idea. Lo que la materia sea en sí misma será un misterio, pero lo que es en cuanto representación es conocimiento, aun con su provisionalidad e imperfección evidentes ${ }^{75}$.

La unidad del alma ocupa un lugar importantísimo en el conjunto de las tesis de la "psicolojia mental" en la Filosofía del Entendimiento, en tanto y en cuanto es condición, como ya se ha adelantado, de la afirmación de operaciones como la sensación, la percepción, el juicio y los procesos lingüísticos:

Las sensaciones, las percepciones, ya lo hemos dicho, existen privativamente en el alma. Si los ojos viesen i la nariz oliese, nada mas habría de común entre mis percepciones de colores i mis percepciones de olores, que entre las percepciones de Pedro i las percepciones de Juan. Somos irresistiblemente movidos a creer que es una misma la sustancia que en nosotros ve, oye, huele, gusta, toca; la que siente placer o dolor, aversión o deseo; la que compara i juzga; la que se percibe a si misma, i esta sustancia es el alma ${ }^{76}$.

Esta unidad del alma es un principio de la epistemología que lingüísticamente se manifiesta en el uso de la palabra "yo", presente en todas las lenguas, y dice Bello que involucra la idea de "un ser idéntico, continuo, uno, percibido por la conciencia"77. Esta es la intuición primordial de la que penden el resto de los procesos, he aquí la unidad del alma manifestada en el yo lingüístico. Sin ese primer saber de sí no es posible saber del otro y de lo otro; no habría representación si el alma no fuera capaz de percibirse intuitivamente a sí misma. Y en este tema Kant es una referencia obligada, pues en la "Deducción trascendental" se pone en juego la unidad trascendental de la apercepción, específicamente en el parágrafo 16:

El yo pienso tiene que poder acompañar todas mis representaciones. De lo contrario, sería representado en mí algo que no podría ser pensado, lo que equivale a decir que la representación, o bien sería imposible o, al menos, no sería nada para mí. La representación

\footnotetext{
75 "no percibimos jamás directamente las modificaciones de la materia; solo las percibimos representativamente por medio de las sensaciones que ella produce en el alma". Bello, A., Filosofía del Entendimiento, p. 28.

76 Ibid., p. 32. Cursivas añadidas.

77 Ibid., p.27.
} 
que puede darse con anterioridad a todo pensar recibe el nombre de intuición. Toda diversidad de la intuición guarda, pues, una necesaria relación con el Yo pienso en el mismo sujeto en el que se encuentra tal diversidad ${ }^{78}$.

Es complicado dar cuenta de los significados del texto kantiano, y su inserción en este contexto de reflexión puede valorarse como un sinsentido, debido a que el filósofo de Könisberg se ocupa preferentemente del sujeto pensante; a riesgo de cargar a cuestas con las críticas y señalamientos de una comparación traída por los cabellos, lo que mueve esta búsqueda de auxilio interpretativo en la epistemología kantiana es el hecho incontrovertible de que postula como necesaria una especie de unidad primigenia que posibilite la existencia de la representación, con conciencia (concepto) o sin ella (simple intuición). Hecho el intento de justificación de la presencia de Kant en este ejercicio de interpretación de la epistemología de Andrés Bello, será bueno aclarar también que, no se trata de asimilar la doctrina epistemológica de Bello a la de Kant, sino de llamar la atención respecto a la apelación a un principio de unidad en el sujeto. Ahora, no debe olvidarse que Bello entiende como necesaria la presencia del juicio tanto en la percepción intuitiva como en la sensitiva, por lo que es imprescindible que la capacidad judicativa entre en juego para que un estado experimentado por el alma se convierta en una percepción ${ }^{79}$. Además, afirma Bello que en todo acto de la conciencia hay "una referencia a nuestra propia alma, a nuestro yo, considerado a un mismo tiempo como sujeto i objeto" 80 .

El alma, el yo, alcanza su grado más alto en la actividad judicativa, porque en todo juicio se concibe una relación y esto es el camino al conocimiento, aunque no sea el conocimiento en sentido estricto porque siempre cabe la posibilidad de equivocarse. Mediante el juicio, el entendimiento concibe y lo hace mediante síntesis: "En todo juicio saca el alma de la yuxtaposición de dos elementos una tercera entidad, distinta de cada uno de ellos i de su mero agregado" ". Insístase, que no se trata de una asimilación a Kant, menos de una igualación, pero, diferencias aparte, hay aspectos doctrinales y de exposición en Bello que permiten pensar en la epistemología crítica kantiana como un valioso aliado para comprender a Bello.

La percepción en la epistemología de Andrés Bello es un todo complejo, porque es el resultado del entrecruce de tres tipos de operaciones, a saber: las de la facultad de intuir, esto es, la capacidad del yo de mirarse a sí mismo; la facultad de sentir, es decir, la capacidad de experimentar sensaciones; y, por último, la facultad de juzgar, con su capacidad de producir síntesis a partir de dos elementos espirituales distintos $^{82}$.

Bello plantea dos mundos que nada tienen en común, pero que son imprescindibles en el juego del conocimiento. El primero, es el de la conciencia, caracterizado por la "unidad perfecta" e "indivisibilidad absoluta"83. El segundo, el de los sentidos, caracterizado por las sensaciones que lo simbolizan y por las percepciones que permiten el paso del sujeto al objeto, el cual consiste en un mundo dominado por la

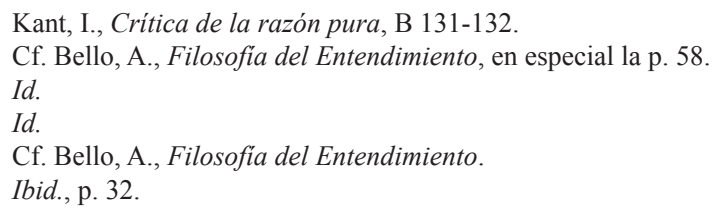


multiplicidad y la extensión ${ }^{84}$. Entre ambos mundos, el caraqueño coloca un puente epistemológico: la referencia, que "convierte lo subjetivo en objetivo", y que "media entre el abismo de la conciencia y el mundo externo" 85 . En consecuencia, es el juicio la clave de la reunión o la armonización de la conciencia con el mundo externo, de la unidad indivisible e inextensa con la multiplicidad, con la extensión: "No percibimos ninguna de las cualidades de un objeto corpóreo, ninguna de las afecciones de nuestros órganos, sino por medio de referencias objetivas, es decir, por medio de juicios" $"$. Si es innegable que la función del juicio adquiere ese gran valor en la epistemología pergeñada por el filósofo caraqueño, no lo es menos que esa función ocurre dentro de la percepción, como ya se anotó ${ }^{87}$. Los juicios, que en principio Bello divide en primarios y sugeridos, están inicialmente ligados a la "experiencia del tacto" $"$, pero entran en la experiencia que involucra al resto de los sentidos. El juicio es el responsable de la representación, por él la sensación es referida a un objeto distinto de ella, y en particular a un objeto material ${ }^{89}$. Sin el juicio no hay percepción, en sentido estricto ${ }^{90}$.

Bello presenta unas consideraciones sobre las funciones del juicio en la configuración de la experiencia que nos hacen pensar en una especie de síntesis intelectiva. ¿En qué se funda esta afirmación?, pues en los siguientes planteamientos: "en todo juicio concebimos una relación"91, "en todo juicio saca el alma de la yuxtaposición de dos elementos una tercera entidad, distinta de cada uno de ellos y de su mero agregado" "92. En el juicio el alma realiza una síntesis a partir de dos elementos de distinta naturaleza y con ello produce la experiencia. He aquí el fundamento de la idea de la facultad judicativa como la responsable de la plena actividad cognoscitiva del alma. Para Bello, las facultades de intuir y sentir son simples o elementales, pero la tercera facultad, la de juzgar, es compleja. Esta tercera facultad contiene dos actos diferentes: la "concepción de una relación" y el "ascenso del alma". De este último pende la sustancia de la experiencia, pues dice Bello que en este acto se "reconoce la realidad de la relación". Con el segundo acto del juicio entra en juego el raciocinio, la prueba y la conclusión ${ }^{93}$, pero también la certidumbre que acompaña a los juicios "cuando versan sobre cualidades corpóreas, o sobre fenómenos del universo material" 94 .

Ahora bien, con respecto a la doctrina sobre los juicios empíricos, Bello deja lugar para el escepticismo en tanto que no entran en las relaciones de evidencia de los entramados demostrativos propios de la deducción. Los juicios que componen las percepciones sensitivas primarias y secundarias no pueden considerarse evidentes, porque tales juicios no se refieren a relaciones espirituales sino a relaciones corporales. $\mathrm{Y}$ jamás hay completa seguridad para afirmar que las relaciones

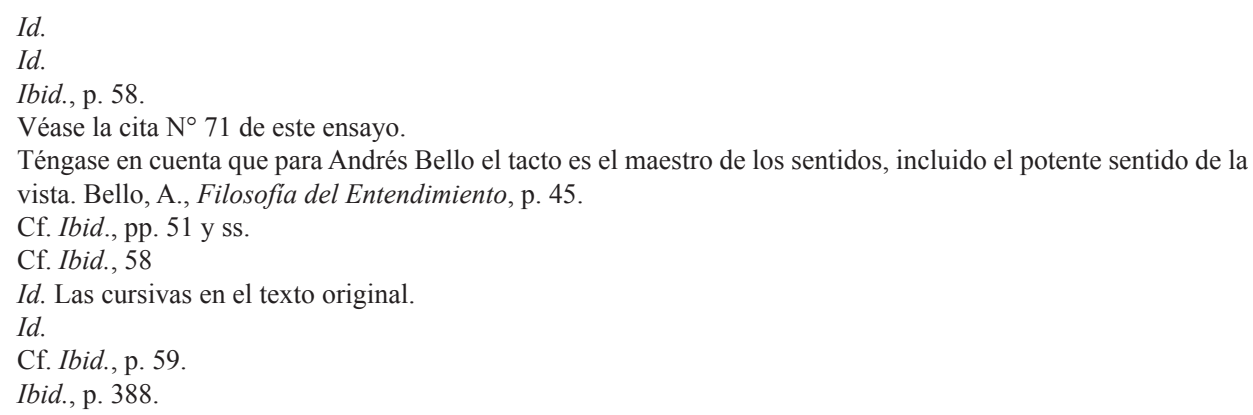


sobre las que versan tengan un correlato en el mundo material ${ }^{95}$. Pero se trata de un escepticismo muy moderado, pues Bello reconoce que esos juicios pueden ser ciertos, gracias al respaldo que brindan tanto la estabilidad de las "leyes que rigen el universo material" como el "principio de las conexiones empíricas" 96 . En todo caso, y para finalizar, estas condiciones respecto de las funciones del juicio en la configuración de la percepción sensitiva ponen de relieve su constante referencia, acertada o fallida, a objetos materiales que pertenecen a un mundo material, esto es, a un ámbito distinto del yo.

\section{Referencias bibliográficas}

Bello, A., Filosofía del Entendimiento, en Obras Completas, Santiago de Chile, Edición del Consejo de Instrucción Pública, V.I., 1881.

Descartes, R., Meditaciones metafisicas, en Descartes, Madrid, Gredos, 2011

García Torres, R., "Anotaciones en torno a la teoría de la percepción en Andrés Bello: una lectura desde el modelo empirista inglés", en Miranda, Bolivar y Bello: tres tiempos del pensar latinoamericano, Caracas, Fundación Konrad Adenauer Stiftung-UCAB, 2007, pp. 293-304.

Hume, D., Investigaciones sobre el conocimiento humano, Madrid, Alianza Editorial, 1980.

Kant, I., Crítica de la razón pura, Madrid, Alfaguara, 2004.

Sellars, W., "Empirismo y la filosofía de lo mental", en Ciencia, percepción y realidad, Madrid, Tecnos, 1971. 